\title{
Statistical Analysis of the Relation Between Inflation and Unemployment in Democratic States Using Spearman's 9 Correlation Coefficient With Application in Albania
}

\author{
Fejzi Kolaneci, Brunilda Hoxhalli \\ University of New York Tirana, Albania \\ "The Relation Between Inflation and Unemployment is an Admirable Illustration of the Scientific \\ Collaboration Between Economists and Mathematicians" \\ Milton Friedman (Nobel Lecture, December 13, 1976)
}

\begin{abstract}
The main purpose of the present study is to investigate the relation between inflation rate and unemployment rate in contemporary democratic states, using Spearman's $९$ correlation coefficient. We apply this method in Albania during the period from January 2005 to December 2014. Some results of the study include: (1) The Central Limit Theorem (CLT) is not applicable for the quarterly inflation rate as well as for quarterly unemployment rate in Albania during the period from January 2005 to December 2014 at the confidence level of $99.99 \%$. The official data for inflation and unemployment contradict the CLT at a very high confidence level of 99.99\%; (2) The inflation process in Albania during the period from January 2005 to December 2014 is an unfair game at the confidence level of 99.2\%; (3) The unemployment process in Albania during the period from January 2005 to December 2014 is an unfair game at the confidence level of $99.99 \%$; (4) The inflation and unemployment in Albania during the period from January 2005 to December 2014 are statistically dependent at the $96 \%$ confidence level; (5) Spearman's correlation coefficient $९=0.387$ indicates a weak positive correlation between inflation and unemployment in Albania during the specified period; and (6) The official data for inflation and unemployment in Albania during the period from January 2005 to December 2014 are consistent with Friedman's hypothesis.
\end{abstract}

Keywords: inflation, unemployment, relation, Spearman's ९, Friedman's hypothesis, Albania

\section{Introduction}

Inflation and unemployment are a major focus on economic policy worldwide.

Inflation is the process of a raise in the general level of prices of goods and services in an economy over a specified period of time. Most frequently, the term "inflation" refers to a rise in the Consumer Price Index (CPI), which measures the prices of a representative fixed basket of goods and services purchased by a typical consumer. The formula for calculating the quarterly inflation rate is:

Fejzi Kolaneci, Full Professor, Department of Mathematics and Natural Sciences, University of New York Tirana. Email: fkolaneci@unyt.edu.al.

Brunilda Hoxhalli, Student, Department of Finance, University of New York Tirana. 


$$
\text { Inflation rate }=\frac{P_{0}-P_{-1}}{P_{-1}} 100 \%
$$

where $P_{0}$ denotes the current average price level and $P_{-1}$ denotes the average price level a quarter ago. During periods of inflation, not all prices and wages rise proportionately. Because they don't, inflation affects income distribution. For example, retirees lose in relation with other groups when inflation is high.

Variations in relative prices lead to more uncertainty, making it harder for firms and companies to make investment decisions about the future. Taxation interacts with inflation to create more distortions. If the tax brackets are not adjusted correctly for inflation, people move into higher and higher tax brackets as their nominal income increases, even if their real income remains the same. Economists generally agree that high rates of inflation are caused by an excessive growth of the money supply. Today, most economists favor a low and stable rate of inflation, because low inflation may reduce the severity of economic recession and the risk of destabilizing the economy (Taylor, 2008; Mankiw, 2010; Giannellis, 2011).

Unemployment, as defined by the International Labour Organization (2007), is the state in which the people are without jobs, they have actively looked for work within the past four weeks, and ready to start work within two weeks. The unemployment rate is the percentage of total labor force unemployed:

$$
\text { Unemployment rate }=\frac{\text { Unemployed } \text { workers }}{\text { Total labour force }}
$$

Economists and mathematicians care about unemployment for two main reasons:

Firstly, unemployment is still often associated with financial and psychological suffering, especially (particularly) when people remain unemployed for long periods of time.

Secondly, unemployment rate provides a signal that the national economy may not be using some of its resources efficiently. If many workers who want to work do not find jobs, then the economy is not efficiently utilizing its human resources.

According to Marx (1863, p. 478), "It is in very nature of the capitalist mode of production to overwork some workers, while keeping the rest as a reserve army of unemployment paupers".

One of the fundamental problems in macroeconomics is the study of the relationship between inflation and unemployment. We will analyze this relationship, over the period from January 2005 to December 2014, in Albania. The sources of the official data are INSTAT and Bank of Albania.

\section{The Central Limit Theorem (CLT)}

If all random samples $\left(x_{1}, x_{2}, \ldots, x_{n}\right)$ of a reasonably large size $n>30$ are selected from any random variable $X$ with finite expectation $\mu$ and variance $\sigma^{2}$, then the probability distribution of the sample mean $\bar{x}$ is approximately normal with expectation $\mu$ and variance $\frac{\sigma^{2}}{n}$. The speed of the convergence to normal distribution is on the order $n^{-0.5}$. This approximation improves with larger samples, as $n \rightarrow \infty$. The convergence to normal distribution is uniform for all real numbers (Kolmogorov, 2002).

CLT explains the reason why many probability distributions tend to be very close to the normal distribution. The amazing thing about CLT is that no matter what the probability distribution of the parent population $X$, the probability distribution of the sample mean approaches a normal curve. 
The remainder of this paper is organized as follows: Section 2 presents the investigation of quarterly inflation rate dynamics; Section 3 presents the investigation of quarterly unemployment rate dynamics; Section 4 provides the analysis of relation between inflation and employment; and Section 5 presents the conclusion.

\section{Dynamics of the Quarterly Inflation Rate}

The data set is the quarterly inflation rate over the period from January 2005 to December 2014 in Albania (see Table A1 in Appendix A). We calculate the statistical parameters for the data (see Table 1).

Table 1

Statistical Parameters Related to Data Set

\begin{tabular}{ll}
\hline Statistics & \\
\hline Sample size & 40 \\
Sample mean & 1.285 \\
$95 \%$ confidence interval for mean & $0.8625 ; 1.7175$ \\
Median & 1.80 \\
Variance & 1.829 \\
Standard deviation & 1.3524 \\
Coefficient of variation & \\
Maximum & 3.30 \\
Minimum & -1.40 \\
Range & 4.70 \\
Interquartile range & 2.40 \\
Skewness & -0.742 \\
Kurtosis & -0.848 \\
\hline
\end{tabular}

In this study, using Kolmogorov-Smirnov-Lilliefors (KSL) test as well as Shapiro-Wilk (SW) test for normality, we test the following hypotheses:

$\mathrm{H}_{0}$ : The quarterly inflation rates for Albania over the period from January 2005 to December 2014 follow a normal distribution.

$\mathrm{H}_{1}$ : The quarterly inflation rates for Albania over this specified period follow a non-normal distribution.

Using SPSS (Version 2013), we find that the computed value of KSL test is 0.213 and the corresponding significance level is 0.000 . Now, we apply the SW test for normality. The computed value of the statistics is $\mathrm{W}=0.870$ and the associated significance is 0.000 .

Decision rule: Reject the null hypothesis $\mathrm{H}_{0}$ at the confidence level of $99.99 \%$. In other words, the CLT is not valid for quarterly inflation rates over the specified period in Albania, at the confidence level of 99.99\%.

Definition. According to Stein (1974) and Vorobiev (1974), the inflation process is said to be a fair game if the successive differences of inflation rates follow a normal distribution with the mean equal to zero.

This important definition has found several applications in economic sciences (see Stein, 1974; Lucas, 2000; Sargent, Williams, \& Zha, 2006; Stock \& Watson, 2007). The successive differences of quarterly inflation rate, over the period from January 2005 to December 2014, in Albania are given in Table A1 in Appendix A. We present the statistical parameters related to this data set (see Table 2). 
Table 2

Statistical Parameters Related to Data Set

\begin{tabular}{ll}
\hline Statistics & \\
\hline Sample size & 40 \\
Sample mean & -0.0175 \\
$95 \%$ confidence interval for mean & $-0.5465 ; 0.5165$ \\
Median & 0.10 \\
Variance & 2.736 \\
Standard deviation & 1.854 \\
Coefficient of variation & \\
Maximum & 3.30 \\
Minimum & -4.30 \\
Range & 7.60 \\
Interquartile range & 1.17 \\
Skewness & -0.503 \\
Kurtosis & 1.078 \\
\hline
\end{tabular}

We test the hypotheses:

$\mathrm{H}_{0}$ : The successive difference of the quarterly inflation rates for Albania, over the period from January 2005 to December 2014, follows a normal distribution.

$\mathrm{H}_{1}$ : The successive difference of the quarterly inflation rates for Albania over this period follows a non-normal distribution.

We apply the KSL test as well as the SW test for normality. The computed value of the KSL test is 0.165 , and the computed value of SW test is $\mathrm{W}=0.937$.

Decision Rule: Reject the null hypothesis $\mathrm{H}_{0}$ at the confidence level of 0.992 . In other words, at the confidence level of $99.2 \%$, the inflation process, over the period from January 2005 to December 2014, in Albania, related to the quarterly inflation rates, is an unfair game.

During the periods of recession, the capitalist economy usually experiences a high unemployment rate. There remains a strong (considerable) theoretical debate regarding the causes, consequences, and optimal solutions for the unemployment. Scientists distinguish between various types and theories of unemployment in capitalist countries: voluntary unemployment versus involuntary unemployment, classical (or real-wage) unemployment, Keynesian unemployment, Marxian unemployment, structural unemployment, frictional unemployment, hidden (or covered) unemployment, and long-term unemployment (see Blanchard, 2011; Mankiw, 2010; Anderton, 2006; Keynes, 2007; Harris, 2005; Marx, 2009).

\section{Dynamics of the Quarterly Unemployment Rate}

The data set is quarterly unemployment rate, over the period from January 2005 to December 2014, in Albania (see Table A1 in Appendix A). We compute the statistical parameters for the data (see Table 3).

Using KSL test as well as SW test for normality, we test the following hypotheses:

$\mathrm{H}_{0}$ : The quarterly unemployment rates over the period from January 2005 to December 2014 follow a normal distribution.

$\mathrm{H}_{1}$ : The quarterly unemployment rates over this specified period follow a non-normal distribution.

Using SPSS (Version 2013), we find that the computed value of KSL statistics is 0.301 and the associated significance is 0.000 . The computed value of SW test is $\mathrm{W}=0.776$ and the corresponding significance is 0.000 . 
Table 3

Statistical Parameters Related to Data Set

\begin{tabular}{ll}
\hline Statistics & \\
\hline Sample size & 40 \\
Sample mean & 14.2025 \\
$95 \%$ confidence interval for mean & $13.6770 ; 14.7280$ \\
Median & 13.8000 \\
Variance & 2.700 \\
Standard deviation & 1.64809 \\
Coefficient of variation & \\
Maximum & 18.60 \\
Minimum & 12.5 \\
Range & 6.10 \\
Interquartile range & 0.97 \\
Skewness & 1.472 \\
Kurtosis & 1.113 \\
\hline
\end{tabular}

Decision Rule: Reject the null hypothesis $\mathrm{H}_{0}$ at the confidence level of $99.99 \%$. In other words, the CLT is not valid for quarterly unemployment rates, over the specified period from January 2005 to December 2014, in Albania, at the confidence level of $99.99 \%$.

The successive differences of quarterly unemployment rates over the period from January 2005 to December 2014 in Albania are given in Table A1 in Appendix A. We present the statistical parameters related to the data set (see Table 4).

Table 4

Statistical Parameters Related to Data Set

\begin{tabular}{ll}
\hline Statistics & \\
\hline Sample size & 40 \\
Sample mean & 0.0850 \\
$95 \%$ confidence interval for mean & $-0.1056 ; 0.2756$ \\
Median & -0.5 \\
Variance & 0.355 \\
Standard deviation & 0.596 \\
Coefficient of variation & \\
Maximum & 1.60 \\
Minimum & -1.50 \\
Range & 3.10 \\
Interquartile range & 0.40 \\
Skewness & 0.715 \\
Kurtosis & 2.204 \\
\hline
\end{tabular}

We test the hypotheses:

$\mathrm{H}_{0}$ : The successive differences of quarterly unemployment rates for Albania over the period from January 2005 to December 2014 follow a normal distribution.

$\mathrm{H}_{1}$ : The successive differences of quarterly unemployment rates for Albania over this period follow a non-normal distribution. 
We apply the KSL test as the SW test for normality. Using SPSS (Version 2013), we find that for both statistical tests, the significance is 0.000 . The computed value of KSL test is 0.198 and the computed value of SW test is $\mathrm{W}=0.875$.

Decision Rule: Reject the null hypothesis $\mathrm{H}_{0}$ at the confidence level of 0.9999. In other words, at the confidence level of $99.99 \%$, the unemployment process, over the period from January 2005 to December 2014, in Albania, related to the quarterly unemployment rates, is an unfair game.

\section{Relation Between Inflation and Unemployment}

Scientific analysis of the relation between inflation and unemployment has gone through three stages. The first stage was the acceptance of a hypothesis associated with the name of the British economist A. W. Phillips, who published a study in 1958 showing a stable negative relation between inflation and unemployment in the United Kingdom by using the data set from 1862 to 1957 (see Philips, 1958). In this study, a smooth curve was constructed, which is known as "Phillips curve": faster inflation is associated with lower unemployment. This relation was widely interpreted as a causal relation that offered a stable trade-off to policy makers. They could choose a low unemployment target. In that case, they would have to accept a high inflation rate. Alternatively, the policy makers could choose a low inflation rate as their target. In that case, they would have to reconcile themselves to higher unemployment rate. Unfortunately for this hypothesis, additional data set from USA, UK, Germany, France, Italy, Japan, Canada, etc. failed to confirm with it. Statistical estimate of the Phillips curve hypothesis has been the subject of an intensive debate. Generally, empirical findings have produced the mixed results. Some scientists found the significant trade-off relation between inflation rates and unemployment rates, while other scientists do not (see Berentsen, Menzio, \& Wright, 2011; Mulligan, 2011; Zaman, Khan, Ahmad, \& Ikram, 2011; Karanassou, Sala, \& Snower, 2010; Herman, 2010; Lacker \& Weinberg, 2007, etc.). On the theoretical side, the attack counter Phillips curve took the form of the natural rate hypothesis of Phelps (1967) and Friedman (1968).

The natural rate hypothesis of Friedman (1968) and Phelps (1967) states that there is some "natural rate of unemployment" and that monetary policy cannot keep unemployment below this level indefinitely. "The natural rate of unemployment", a term introduced by Friedman (1968) to parallel Knut Wickell's "natural rate of interest", is not a constant real number, but depends on random variables such as effectiveness of the labor market, the extent of competition of monopoly, the barriers of encouragements to working in various occupations, and so on. The natural rate hypothesis represents the second stage of the relation between inflation and unemployment. This hypothesis contains the Phillips curve as a special case. The natural rate hypothesis implicitly assumes that the relation between inflation and unemployment is weakly stationary process in the Doob-Rozanov sense.

In recent years, in USA, UK, Germany, France, Italy, Japan, Canada, etc., higher inflation rate has often been accompanied by higher unemployment rate, not lower unemployment rate as the Phillips curve would suggest, nor approximately the same unemployment rate as the natural rate hypothesis would suggest. This is the third stage of the relation between inflation and unemployment. According to the Friedman's hypothesis, there is a positive association between inflation and unemployment (see Friedman, 1976). In the contemporary literature, Friedman's hypothesis states that, "If there are disturbances to aggregate supply rather than aggregate demand, then high inflation and high unemployment can occur together" (see Mankiw, 2010; Karanassou et al., 2010, pp. 29-30). 
At the confidence level of $99.99 \%$, quarterly inflation rate and quarterly unemployment rate in Albania during the period from January 2005 to December 2014 follow a non-normal distribution. Therefore, we cannot use Pearson's correlation coefficient to investigate (for Albania's case) the relation between inflation and unemployment. However, we can use Spearman's 9 correlation between quarterly inflation rate (denoted by $Y$ ) and quarterly unemployment rate (denoted by $X$ ), as it does not rely on any assumptions on the probability distributions of random variables $X$ or $Y$ or the joint distribution of the vector random variable $(X, Y)$ (see Hollander \& Wolfe, 1973; Myers \& Well, 2003; Corder \& Foreman, 2014).

Spearman's $\bigcirc$ rank correlation coefficient is a non-parametric measure of statistical dependence between two random variables $X$ and $Y$. Spearman's $९$ assesses how well the relation between $X$ and $Y$ can be described using a monotonic function.

Spearman's $\bigcirc$ correlation coefficient is appropriate for both continuous and discrete random variables. By definition, Spearman's $९=९(X, Y)$ is calculated as the Pearson's correlation coefficient between ranked variables (see Corder \& Foreman, 2014; Myers \& Well, 2003). For an arbitrary random sample $\left(x_{1}, y_{1}\right)$, $\left(x_{2}, y_{2}\right), \ldots,\left(x_{n}, y_{n}\right)$ selected from the random vector $(X, Y)$, the $n$ raw scores $\left(x_{i}, y_{i}\right)$ are converted to ranks $\left(X_{i}, Y_{i}\right)$, and Spearman's $\bigcirc$ correlation coefficient is computed by the formula:

$$
\rho=1-\frac{6\left(d_{1}^{2}+d_{2}^{2}+\cdots+d_{n}^{2}\right)}{(n-1) n(n+1)}
$$

where $d_{i}=X_{i}-Y_{i}$ denotes the difference between ranks.

If $Y$ tends to increase when $X$ increases, then $९>0$.

If $Y$ tends to decrease when $X$ increases, then $\mathrm{Q}<0$.

If no tendency for $Y$ to neither increase nor decrease when $X$ increases, then $\$=0$.

The sign of $\bigcirc$ indicates the direction of association between random variables $X$ and $Y$.

In applications, $r$ denotes the observed value of 9 . That means: $r$ denotes random sample Spearman's correlation coefficient and $\boldsymbol{Q}$ denotes population Spearman's correlation coefficient.

Under the null hypotheses:

$\mathrm{H}_{0}: \mathrm{S}=0$ (statistical independence between $X$ and $Y$ ).

$\mathrm{H}_{1}: \Omega \neq 0$ (statistical dependence between $X$ and $Y$ ).

The appropriate test statistic is "student's $t$ distribution":

$$
t=r \sqrt{\frac{n-2}{1-r^{2}}}
$$

where $n-2$ denotes the degrees of freedom (see Kendall \& Stuart, 1973).

The data set consists of quarterly inflation rate and quarterly unemployment rate in Albania during the period from January 2005 to December 2014 (see Table A1 in Appendix A). The sample size is $n=40$.

Using SPSS (Version 21, 2013), we compute the sample Spearman's correlation coefficient $r=0.387$.

We test the hypotheses:

$\mathrm{H}_{0}: \mathrm{S}=0$.

$\mathrm{H}_{1}: \Theta \neq 0$ (two-tailed test).

Given the significance level $\alpha=0.04$.

The appropriate test statistics is $t$ distribution: 


$$
t=r \sqrt{\frac{n-2}{1-r^{2}}}
$$

with $\mathrm{df}=n-2$.

The observed value of test statistics is:

$$
t=0.387 \sqrt{\frac{38}{1-0.387^{2}}}=2.587
$$

The critical value of $t$ distribution is $t_{c}=t_{\alpha / 2}(\mathrm{df})=t_{0.02}(38)=2.4286$.

Decision Rule: $|t|=2.587>t_{c}=2.4286$.

Reject the null hypothesis $\mathrm{H}_{0}: \mathrm{S}=0$ at the confidence level $\gamma=1-\alpha=96 \%$.

In other words, the quarterly inflation rates and unemployment rates in Albania during the period from January 2005 to December 2014 are statistically dependent random variables at the confidence level of $96 \%$.

Spearman's correlation coefficient $r=0.387$ indicates a weak positive correlation between quarterly inflation rate and quarterly unemployment rate in Albania during the period from January 2005 to December 2014. Therefore, the Friedman's hypothesis holds (accepted) for the relation between inflation and unemployment.

\section{Conclusion}

This study is concerned with three types of dynamic macro models over the period from January 2005 to December 2014 in Albania:

(1) Monetary macroeconomic models that focus on inflation dynamics;

(2) Labor macroeconomic models that focus on unemployment dynamics;

(3) Correlative models that seek to explain the relation between quarterly inflation rates and quarterly unemployment rates.

At the very high confidence level of $99.99 \%$, the Kolmogorov's CLT is not valid for quarterly inflation rates. At the confidence level of $99.2 \%$, the inflation process, related to the quarterly inflation rates, is an unfair game. At the very high confidence level of $99.99 \%$, the Kolmogorov's CLT is not valid for quarterly unemployment rates. At the same confidence level of $99.99 \%$, the unemployment process, related to the quarterly unemployment rates, is an unfair game.

The contradiction between quarterly inflation rates or quarterly unemployment rates and the CLT is very serious, as this theorem is a fundamental statement of modern probability theory.

This contradiction (with CLT) implies that we cannot use Pearson's correlation coefficient to investigate the relation between inflation and unemployment in Albania during the specified period. However, we can use Spearman's 9 correlation coefficient.

The Ministry of Finance and Bank of Albania have the responsibility for "unfair game" inflation process in Albania over the period from January 2005 to December 2014. In order to successfully fight the inflation process or unemployment process as an "unfair game", some concrete actions must be suggested to the Albanian Government and Bank of Albania.

The main reasons for the departure of quarterly inflation rates and quarterly unemployment rates from normal distribution as well as the "unfair game" inflation process and unemployment process in Albania's market during the period from January 2005 to December 2014, are: 
(1) Excess demand for several sectors of the economy (goods, services, money, financial assets, labor force, etc.);

(2) National debt and government expenditure;

(3) Monetary policy;

(4) Unemployment rate dynamics for labor costs;

(5) Level of corruption: Detection and penalty of corrupted activities;

(6) Money laundering process;

(7) How conflicting interests are solved;

(8) Legislative changes;

(9) Imported inflation, economic recession, financial crisis.

The "unfair game" inflation process and "unfair game" unemployment process in Albania during the period from January 2005 to December 2014 implies economic loss for Albanian families: the mean value of this loss during the specified period is approximately estimated 25,000 Albanian Lekë per family/per month.

An obvious feature of our study is the severity of rejecting the fair game hypothesis in Albania's market during 10 years (from January 2005 to December 2014). Therefore, there is a suspect for the presence of excessive speculation in Albania's market, associated with excessive speculators.

Excessive speculation causes sudden or unreasonable fluctuations or unwarranted changes in the price of commodity. Excessive speculation drives prices away from the competitive price consistent with available information.

It is found, for Albanian economy during the period from January 2000 to December 2012, that an increase of $1 \%$ in annual unemployment rate, on average, leads to an increase of $2.3 \%$ in the annual inflation rate (see Kolaneci \& Sota, 2013).

The inflation and unemployment in Albania during the period from January 2005 to December 2014 are statistically dependent, at the $96 \%$ confidence level.

Spearman's correlation coefficient $r=0.387$ indicates a weak positive correlation between quarterly inflation rate and unemployment rate in Albania during the specified period. The data set, presented in Table A1 in Appendix A, is consistent with famous Friedman's hypothesis: If there are disturbances to aggregate supply rather than aggregate demand, then high inflation and high unemployment can occur together. This situation includes a plethora of economic-social-technological conditions such that: economic crisis, privatization process, company bankruptcy, industrial decline, real-wage unemployment (classical unemployment), Marxian unemployment, seasonal unemployment, frictional unemployment, hidden (or covered) unemployment, technological unemployment, political corruption, and excessive speculation.

Are the "unfair game" inflation process and "unfair game" unemployment process for Albania's case transitory or persistent? The answer to this question is crucial for Albanian people.

\section{References}

Anderton, A. (2006). Economies (4th ed.). Ormskirk: Causeway Press.

Berentsen, A., Menzio, G., \& Wright, R. (2011). Inflation and unemployment in the long run. American Economic Review, 101(1), 371-398.

Blanchard, O. (2011). Macroeconomics. USA: Pearson Education.

Corder, G. W., \& Foreman, D. I. (2014). Nonparametric statistics for non-statisticians: A step-by-step approach. Hoboken, NJ: John Wiley \& Sons. 
Friedman, M. (1968). The role of monetary policy. American Economic Review, 58(1), 1-17.

Friedman, M. (1976). Inflation and unemployment. Nobel Memorial Lecture, December 13, 1976.

Giannellis, N. (2011). Nonlinearity and inflation rate differential persistence: Evidence from the Eurozone. University of Ionnina.

Harris, S. E. (2005). The new economies: Keynes'influence on theory and public policy. Kessinger Publishing.

Herman, E. (2010). Inflation and unemployment in the Romanian economy. Annals of the University of Petrosani, Economics, $10(2), 157-170$.

Hollander, M., \& Wolfe, D. A. (1973). Nonparametric statistical methods. New York, NY: John Wiley \& Sons.

International Labour Organization. (2007). Resolution concerning statistics of the economically active population, employment, unemployment and underemployment. Retrieved from http://www.ilo.org/public/english/bureau/stat/download/res/ecacpop.pdf

Karanassou, M., Sala, H., \& Snower, D. J. (2010). Phillips curves and unemployment dynamics: A critique and a holistic perspective. Journal of Economic Surveys, 24(1), 1-51.

Kendall, M. G., \& Stuart, A. (1973). The advanced theory of statistics (Vol. 2). USA: Charles Griffin \& Co. Ltd.

Keynes, J. L. (2007). The general theory of employment, interest and money. Basingstoke, Hampshire: Palgrave Macmillan.

Kolaneci, F., \& Sota, L. (2013). Investigation of the Lucas loss functions in Albania during the period 2000-2012.

Kolmogorov, A. N. (2002). Probability theory. Moscow: Nauka.

Lacker, J. M., \& Weinberg, J. A. (2007). Inflation and unemployment: A layperson's guide to the Phillips curve. Economic Quarterly, 93(3), 201-227.

Lucas, R. E. (2000). Inflation and welfare. Econometrica, 68(2), 247-274.

Mankiw, N. G. (2010). Macroeconomics (7th ed.). Worth Publishers.

Marx, K. (1863). Theory of surplus value (p. 478).

Marx, K. (2009). Capital: An abridged edition (Ed. D. McLellan). Oxford, UK: Oxford Paperbacks.

Mulligan, R. F. (2011). An Austrian rehalibization of the Phillips curve. Cato Journal, 31(1), 87-98.

Myers, J. L., \& Well, A. D. (2003). Research design and statistical analysis (2nd ed.). Mahwah, NJ: Lawrence Erlbaum.

Phelps, E. S. (1967). Phillips curves, expectations of inflation and optimal unemployment over time. Economica, 34(135), 254-281.

Phillips, A. W. (1958). The relation between unemployment and the rate of change of money wage rates in the United Kingdom, 1861-1957. Economica, 25(100), 283-299.

Sargent, T. J., Williams, J., \& Zha, T. (2006). Shocks and governement beliefs: The rise and fall of American inflation. American Economics Review, 96(4), 1193-1224.

Stein, J. L. (1974). Unemployment, inflation, and monetarism. American Economic Review, 64(6), 867-887.

Stock, J. H., \& Watson, M. W. (2007). Why has U.S. inflation become harder to forecast? Journal of Money, Credit and Banking, $39(\mathrm{~s} 1), 3-33$.

Taylor, T. (2008). Principles of economics: Economics and the economy. USA: Freeload Press.

Vorobiev, N. N. (1974). Soveremennoe sostojanie teorii igr. Uspehi Matematiçeskih Nauk, 44(1), 73-98.

Zaman, K., Khan, M. M., Ahmad, M., \& Ikram, W. (2011). Inflation, unemployment and the NAIRU in Pakistan (1975-2009). International Journal of Economics and Finance, 3(1), 245-254. 


\section{Appendix A}

Table A1

Quarterly Inflation Rate, Successive Differences of Quarterly Inflation Rate, Quarterly Unemployment Rate, and Successive Differences of Quarterly Unemployment Rate in Albania

\begin{tabular}{|c|c|c|c|c|c|}
\hline Year & Quarter & Inflation rate $(\%)$ & $\begin{array}{l}\text { Successive differences } \\
\text { of inflation rate }(\%)\end{array}$ & Unemployment rate $(\%)$ & $\begin{array}{l}\text { Successive differences } \\
\text { of unemployment rate }(\%)\end{array}$ \\
\hline \multirow{4}{*}{2005} & Q1 & 3.3 & 1.3 & 13.1 & -1.5 \\
\hline & Q2 & -1 & -4.3 & 12.7 & -0.4 \\
\hline & Q3 & -1.4 & -0.4 & 12.6 & -0.1 \\
\hline & Q4 & 1.9 & 3.3 & 14.2 & 1.6 \\
\hline \multirow{4}{*}{2006} & Q1 & 2 & 0.1 & 14 & -0.2 \\
\hline & Q2 & 0.2 & -1.8 & 13.9 & -0.1 \\
\hline & Q3 & -1.2 & -1.4 & 13.8 & -0.1 \\
\hline & Q4 & 1.8 & 3 & 13.7 & -0.1 \\
\hline \multirow{4}{*}{2007} & Q1 & 2.2 & 0.4 & 13.7 & 0 \\
\hline & Q2 & -0.8 & -3 & 13.5 & -0.2 \\
\hline & Q3 & 0.4 & 1.2 & 13.2 & -0.3 \\
\hline & Q4 & 1.7 & 1.3 & 13.4 & 0.2 \\
\hline \multirow{4}{*}{2008} & Q1 & 2.4 & 0.7 & 13.1 & -0.3 \\
\hline & Q2 & -0.3 & -2.7 & 12.7 & -0.4 \\
\hline & Q3 & -0.8 & -0.5 & 12.6 & -0.1 \\
\hline & Q4 & 1.2 & 2 & 12.5 & -0.1 \\
\hline \multirow{4}{*}{2009} & Q1 & 1.8 & 0.6 & 12.7 & 0.2 \\
\hline & Q2 & -0.1 & -1.9 & 12.7 & 0 \\
\hline & Q3 & -0.7 & -0.6 & 12.8 & 0.1 \\
\hline & Q4 & 2.2 & 2.9 & 13.7 & 0.9 \\
\hline \multirow{4}{*}{2010} & Q1 & 3 & 0.8 & 13.9 & 0.2 \\
\hline & Q2 & -1 & -4 & 13.8 & -0.1 \\
\hline & Q3 & -0.6 & 0.4 & 13.5 & -0.3 \\
\hline & Q4 & 1.8 & 2.4 & 13.5 & 0 \\
\hline \multirow{4}{*}{2011} & Q1 & 2 & 0.2 & 14 & 0.5 \\
\hline & Q2 & 2.5 & 0.5 & 13.8 & -0.2 \\
\hline & Q3 & 2.3 & -0.2 & 13.9 & 0.1 \\
\hline & Q4 & 2.4 & 0.1 & 13.9 & 0 \\
\hline \multirow{4}{*}{2012} & Q1 & 2.4 & 0 & 14 & 0.1 \\
\hline & Q2 & 2.4 & 0 & 13.8 & -0.2 \\
\hline & Q3 & 2.7 & 0.3 & 14.1 & 0.3 \\
\hline & Q4 & 2.4 & -0.3 & 14.1 & 0 \\
\hline \multirow{4}{*}{2013} & Q1 & 2.5 & 0.1 & 14.8 & 0.7 \\
\hline & Q2 & 2.2 & -0.3 & 16.4 & 1.6 \\
\hline & Q3 & 1.5 & -0.7 & 17.2 & 0.8 \\
\hline & Q4 & 1.5 & 0 & 17.1 & -0.1 \\
\hline \multirow{4}{*}{2014} & Q1 & 1.9 & 0.4 & 18.6 & 1.5 \\
\hline & Q2 & 1.6 & -0.3 & 17.7 & -0.9 \\
\hline & Q3 & 1.8 & 0.2 & 17.4 & -0.3 \\
\hline & Q4 & 1.3 & -0.5 & 18 & 0.6 \\
\hline
\end{tabular}

